\title{
Mobile and Context-Aware GeoBI Applications: A Multilevel Model for Structuring and Sharing of Contextual Information
}

\author{
Belko Abdoul Aziz Diallo, Thierry Badard, Frédéric Hubert, Sylvie Daniel \\ Centre de Recherche en Géomatique, Université Laval, Québec, Canada \\ Email: belko-abdoul-aziz.diallo.1@ulaval.ca, Thierry.Badard@scg.ulaval.ca,Frederic.Hubert@scg.ulaval.ca, \\ Sylvie.Daniel@scg.ulaval.ca
}

Received February 27, 2012; revised March 26, 2012; accepted April 23, 2012

\begin{abstract}
With the requirements for high performance results in the today's mobile, global, highly competitive, and technology-based business world, business professionals have to get supported by convenient mobile decision support systems (DSS). To give an improved support to mobile business professionals, it is necessary to go further than just allowing a simple remote access to a Business Intelligence platform. In this paper, the need for actual context-aware mobile Geospatial Business Intelligence (GeoBI) systems that can help capture, filter, organize and structure the user's mobile context is exposed and justified. Furthermore, since capturing, structuring, and modeling mobile contextual information is still a research issue, a wide inventory of existing research work on context and mobile context is provided. Then, step by step, we methodologically identify relevant contextual information to capture for mobility purposes as well as for BI needs, organize them into context-dimensions, and build a hierarchical mobile GeoBI context model which 1) is geo-spatial-extended; 2) fits with human perception of mobility; 3) takes into account the local context interactions and information-sharing with remote contexts; and 4) matches with the usual hierarchical aggregated structure of BI data.
\end{abstract}

Keywords: Context-Awareness; Decision Support System (DSS); Mobile Geospatial Business Intelligence (GeoBI); Decision-Making; Relevant Contextual Information; Context Dimensions; Context Modeling; Context Sharing; Context Structuring; BI Data

\section{Introduction}

In the today's global, highly competitive and technologybased business world, business professionals are not only becoming increasingly mobile, moving to places where business requires them (opportunities to catch, problems to deal with, meetings to attend, etc.), but they also have to keep looking after the fluctuations and trends of their businesses at anytime from anywhere, via mobile applications and devices (smart phones, PC pockets, etc.), in order to be able to take the right decision at the right time and hence to reach their business goals. To assist these offsite business people, suitable mobile decision support systems (DSS) are required.

Thanks to the emergence of pervasive and mobile computing technologies, several mobile DSSs have been proposed amongst: Hand-OLAP [1], Mobile-OLAP [2], Spatial OLAP Mobile [3], MoBI [4], and Go! Mobile [5]. These solutions are actually mobile Business Intelligence Systems (BIS) built upon data warehouse and OLAP technologies. Business Intelligence Systems (BIS) has emerged from the 1990's [6] as convenient means to collect, store and compute the transactional data soup ${ }^{1}$ into summarized and meaningful information for decision makers.

Based on cross-readings of different authors and practitioners ([7-15]), we define Business intelligence (BI) as the activity or the process of intelligently gathering, integrating, aggregating, storing, processing and analyzing business data in order to extract or find out synthesized, pertinent and meaningful information and knowledge in a way that improves business decision making. Criteria specifying what is relevant and meaningful for an organization are often predefined and measured through metrics and key performance indicators $(K P I)$ which can be displayed in dashboards, scorecards, reports, etc., as crosstabs, diagrams, and maps.

Business Intelligence Systems (BIS) refer then, to the adequate computer-based tools and technologies (e.g. Extract, Transform and Load (ETL) tools, data ware-

${ }^{1}$ Data soup is an expression introduced by [56] to emphasis the huge amount of detailed and raw data scattered in multiple various data sources resulting from mass computerization and the advent of information and communication Technologies (ICT). 
housing, Online Analytical Processing - OLAP — data mining, reporting, dashboarding, etc.) which, when harmoniously arranged, can support the implementation of the analytical process in a comprehensive, reliable and effective way, in order to assist decision makers in monitoring and analyzing their businesses.

Since business intelligence and mobility are concerned, geospatial features are obviously involved in, such as: international or national borders (e.g. continents, countries, provinces, etc.); transportation infrastructures (roads, railways, planes, trains, etc.); place names, addresses or zip codes (of sales, deliveries, meetings, clients, partners, companies, services, etc.); GPS coordinates of geo-localized POIs, routes and directions to follow, etc. According to [16], about $80 \%$ of data store or corporate data warehouse has a geo-spatial dimension. That geo-spatial part of business data may be more suitably exploited if analyzed and represented by BI Systems coupled with maps and GIS capabilities. This geospatial-extended business intelligence is known as Geospatial Business Intelligence (GeoBI). Furthermore, GeoBI systems, by providing an intelligent coupling of geospatial and Business Intelligence technologies have specifically extended the capacity of data analysis by bringing spatio-temporal data support, cartographic visualization and spatial analysis capabilities. Except Spatial OLAP Mobile [3], the mobile DSSs aforementioned are not geospatially-extended.

Considering mobility as the fact of getting far (remoteness) from the organization's resources (humans, data, work tools, etc.) and losing a certain direct contact with them, all the mobile BI Systems listed previously have then been primarily designed to provide mobile decision makers with access from anywhere at any time to their business data and analysis tools, remotely as if they were in their office: no matters where the user is and what is around him. Therefore, if they conveniently palliate to the need of data access and analysis once on the ground ([14]), they do not really exploit the user's location, and ignore his dynamic changing work context where some events may influence or improve his initial insights (e.g. traffic congestion, available services, weather conditions, noise, people met, local security, business or administrative alerts, etc.).

To give an improved support to mobile business professionals, it is necessary to go further than just allowing a simple remote access to a Business Intelligence platform. An actual context-aware mobile Geospatial Business Intelligence (GeoBI) system that fully takes into account all aspects of mobility is required. Indeed, we believe that in addition to being BI-based, a suitable mobile DSS should be, for well-informed and environment-adapted decisions: 1) geospatial-extended, i.e. GeoBI-based, to integrate geospatial aspects of business and mobility; and 2) context-based, to capture the user's reality in mobility.

As it is known, professional mobility is usually justified by the mobile worker's need to experiment a physiccal proximity [17] to resources, problems or opportunities such as meeting persons (customers, suppliers, partners, etc.), scrutinizing more closely some phenomena (pollution, traffic, sales on the field, etc.), visiting POIs, etc., in order, among other things, to acquire more accurate and precise information from what he sees, hears, smells, feels, or senses within his local work context, and in consideration of influences of remote contexts. This contextual information may be of any kind and related to business, social, environmental, geospatial or technological issues so that some part of the information may escape the mobile worker's attention while the another part may ask for more cognition effort to get managed and understood. A context-aware mobile GeoBI system should help capture, filter, organize and structure it into a human perception-compatible context model so that it would be exploited in combination with BI data structures and models (data warehouses, data cubes, etc.) to provide the users with appropriate analytics on which they can base their decision process and take fully informed decisions.

Modeling and structuring mobile contextual information into suitable context models is still a research issue, mainly for context-based mobile GeoBI solutions. The wide inventory of existing research work on context and mobile context we provide in the first part of this paper shows that there is still neither a model nor an inventory about relevant contextual information for mobile GeoBI contexts. In the rest of the paper, we identify relevant contextual information for mobility issues as well as for BI needs and organize them into context-dimensions. Then, we propose and build step by step, a hierarchical mobile GeoBI Context Model (named GeoMoBICoMod) which 1) is geo-spatially-extended; 2) fits with human perception of mobility; 3) takes into account the local context interactions and information-sharing with some remote contexts; and 4) matches with the usual hierarchical aggregated structure of BI data.

\section{Related Works on Context and Mobile Context}

The notion of context is widespread in manifolds domains, but is often differently apprehended and defined even in the same area of research. Therefore, there is still no consensus among authors on what should be a context.

\subsection{Context Definitions}

Current definitions of context are ranging from human 
experience to robotics. For instance, considering the user's experience, Bolchini et al. [18] defined context as "an active process dealing with the way humans weave their experience within their whole environment, to give it meaning."; whereas in robotic vision, Lombardi et al. [19] considered that "context is what imposes changes to the variable part of a system, (...) a particular configuration of internal parameters".

From a mobile computing standpoint in which we are interested in, Chen and Kotz [20] adopted a softwarebased definition: "Context is the set of environmental states and settings that either determines an application's behavior or in which an application event occurs and is interesting to the user". This technology-oriented definition implicitly refers to the concept of context-awareness of applications.

\subsection{Context-Awareness}

The notion of context-awareness originates from Schilit et al. [21] who introduced context-aware applications as software that "adapts according to the location of use, the collection of nearby people, hosts, and accessible devices, as well as to changes to such things over time". From the viewpoint of several works, context awareness refers to the ability of an application or a device to adapt itself to its environment, 1) automatically (active awareness); 2) at the user request (passive awareness); or 3) based on the user's preferences (personalization and adaptability, i.e. the possibility for users to configure how the application should behave according to the context) [22,23]. According to Dey [24] "a system is context-aware if it uses context to provide relevant information and/or services to the user, where relevancy depends on the user's task."

History records that the Olivetti Research group and Xerox Parc group, with their pioneering work respecttively on active badge location systems [25] and ubiquitous computing experiment [26], were the firsts to issue context-aware systems. In the case of active badges [25], the authors proposed the use of infrared active badge for a direct localization of office staff. The ubiquitous computing experiment [26] was about locating and displaying people - their faces - on an indoor dynamic map (rooms) to follow people's activity. Over the time, research work on context and context-awareness has increased tenfold and embraces various domains such as context-based business activities (e.g. [27,28]), mobile work (e.g. [29, 30]), mobile web ([31]), mobile mapping (e.g. [32,33]), and mobile context-aware computing in general (e.g. $[34,35])$, etc. But there is still not yet works on context-based GeoBI to our knowledge.

To be context-aware, applications have to sense and/or be aware of contextual information identified as relevant for the targeted purpose. In the literature, some contextual information has been inventoried by different authors as being part of context.

\subsection{Context Content: Major Contextual Information and Context Dimensions in the Literature}

Several works have proposed a set of contextual information a context might contain. Context content can be viewed as the whole set of contextual information involved in that context. According to Dey et al. [36], contextual information is any information which can characterize the situation of a relevant entity (e.g. the user) for the application. Moreover, the work of Winograd [37] on context architectures highlighted that it might be a difference between contextual information, and the environment settings: "something is context because of the way it is used in interpretation, not due to its inherent properties". Thanks to the survey of Chen and Kotz [20] on "context-aware mobile computing", it is also known that a context content (or a part) might be active "that influences the behaviors of an application", or passive context (e.g. environment settings).

In the literature, beyond these different natures of contextual information, context content is generally determined according to the context-aware application purpose and its design standpoint. Several authors have proposed and listed contextual information they counted as relevant, generally by organizing it into models or context dimensions, i.e. main categories of contextual information (e.g. social context, time context). These main categories are generally described with key elements or sub-categories (e.g. weather, seasons for time context) depending on the standpoint and the targeted activity (purpose) authors considered. For example, while $[36,38]$ considered context in general as regarding location, people and objects, [30] organized it, in the case of mobile work, into five main dimensions: Task context (interactions with the system, tasks related to the work); Social context (people, work community, culture); Infrastructural context (technologies, device, system, etc.); Spatial context (location, temperature, noise, etc.); and Temporal context (schedules, deadlines, etc.).

Regarding context-based business activities, some few works are emerging. Those we found are mainly oriented to online activities. The first one [27] proposed a "context model for B2B collaborations" for online exchanges. The paper identified three main dimensions with several sub-dimensions or key elements: User/Company (User expression, Profile, Industry Sector, Product Service, etc.); Temporal context (Time Expression, Periodicity, Lead time, etc.); and Location (Geographical Expression, 
Transportation Mode, Political Stability Index, Tariffs, etc.). Interested in context-based e-commerce, the second one [28] defined such context as a combination of two main dimensions (user context and business context) characterized by other context dimensions as follow:

- User context (Personal context, Task context, Environmental context, Social context).

- Business context (Product Context [product category, price, features], Business rules).

Tackling context according to human spatial cognition, [39] and [40] elaborated context into three hierarchical spaces.

From the viewpoint of [39], human beings think about the real space by dividing it into hierarchical mental spaces:

- The body space which is the mental representation of the body shape and postures through body's junctions (head, arm, hand, chest, back, leg, foot) and senses: eyes, ears, mouth, etc.;

- The space around the body which is the space of things that can be seen or reached. It is referred to through three main axes in a 3D frame: head/feet, front/back, and left/right axes;

- The navigation space which is the less known and sensed space with simplified or aggregated spatial information referred to by the means of landmarks, paths, links and nodes.

Considering the perception of life space, [40] have also identified three hierarchical spaces, but meaningfully different from those identified by [39]:

- The vista space which is the space around the body where activities are regularly carried out such as home or work place;

- The local displacement reinforcement space that is the frequently visited space (usually by feet) around the vista space;

- The enlarged displacement reinforcement space which "consists of the region that embraces both the activity islands beyond the local displacement reinforcement region and the local reinforcement region itself'.

In the case of mobile context-aware computing, [34] and [35] similarly organize context content into five dimensions, but with some different dimensions. The similar dimensions are:

- User context (username for [34]; goals, tasks, intentions, etc. for [35]);

- Location context (position, GPS-coords) for [34] or Physical context (objects) for [35];

- Time context (current time, system clock) for [34] or Temporal context (time) for [35].

The rest of dimensions are different. While [34] identified Device context (device identifier, device type) and Network context (network connection types, bandwidth) for the purpose of making remote devices communicate,
[35] proposed Social context (people) and Computing context (connectivity, network capacity, processors, etc.) as relevant in the purpose of multidisciplinary contextaware computing.

Besides, it can be noticed that in addition to structuring contextual information into dimensions, [34] has additionally separated contextual information related to mobile devices into local context ("the context of the location device") and remote context ("the context of remote devices"). This location-based contextualization of contextual information is relevant for us and will be exploited and extended to mobile geospatial business intelligence aspects later in Section 4.2 to build step by step a hierarchical and multilevel model for mobile GeoBI contexts.

Other main works proposing some relevant context contents are reviewed in Table $\mathbf{1}$ which provides in fact, a summary of a somehow wide inventory. The criteria of context-awareness, mobility, and enough detailed description of contextual information organized or not into models have been mainly considered in addition to originality (specific viewpoint different from others). Table 1 presents contextual information listed by authors. Contextual information is presented in the form of thematic-based groups known as dimensions (bold, italic, and underlined terms in the table), each dimension containing (between brackets in the table) some key and detailed contextual elements identified by authors, if any.

From this large inventory of work on context and mobile context, it can be noticed that there is still neither a model nor an inventory about relevant contextual information and dimensions for a mobile Business Intelligence Context. Works of [27,28], even if related to business activity, are not dedicated to mobile activities, and seem to be too restrictive and not easily adaptable and expandable to mobile business intelligence, according to our viewpoint. For instance, they do not integrate the fact that with the globalization of economy, a given local business context (e.g. Hong Kong stock exchanges) may be influenced by a remote one (e.g. Wall Street stock exchanges). In addition, the lack of contextual information in their business contexts about markets, resources, and strategies (e.g. objectives, actions plan, metrics, etc.) regarding organizations (government, companies, etc.) means that a deep reorganization would be required to extend them for business intelligence purpose.

It can also be observed that works on context are mainly focused on applications' context-awareness. But, since users are also sensitive to events occurring in a mobile context (this is known as situation awareness), it should be relevant to consider how applications' contextawareness and users' situation-awareness could be connected in order to substantially enhance decision-making in mobile environments. 
Table 1. Context dimensions and key elements in the literature.

\begin{tabular}{|c|c|c|c|}
\hline Standpoint & Purpose & Authors & $\begin{array}{l}\text { Context content: Context dimensions and their key and detailed elements listed by } \\
\text { authors }\end{array}$ \\
\hline \multirow[t]{4}{*}{ Context in general } & Any activity & {$[36,38]$} & -Location; -People (identity, state); -Objects (computational and physical); \\
\hline & & {$[41]$} & $\begin{array}{l}\text {-Human factors (user, social environment, tasks); -Physical environment } \\
\text { (Conditions [light, pressure, acceleration, temperature], infrastructures, location); }\end{array}$ \\
\hline & & {$[34]$} & $\begin{array}{l}\text { Local and Remote contexts composed of: } \\
\text {-Time context (current time, system clock); -Location context (position, } \\
\text { GPS-coordinates); } \\
\text {-Device context (device identifier, device type); -User context (user name); } \\
\text {-Network context (network connection types, bandwidth); }\end{array}$ \\
\hline & & {$[35]$} & $\begin{array}{l}\text {-User context (goals, tasks, intentions, history, preferences); -Physical context (objects); } \\
\text {-Social context (people); -Temporal context (time); } \\
\text {-Computing context (connectivity, network capacity, computing costs, display \& } \\
\text { input, processors); }\end{array}$ \\
\hline \multirow[t]{4}{*}{$\begin{array}{l}\text { Mobile } \\
\text { context-aware } \\
\text { computing }\end{array}$} & $\begin{array}{l}\text { Any mobile } \\
\text { activity }\end{array}$ & {$[42]$} & $\begin{array}{l}\text { User context divided into: } \\
\text {-Environmental context (users surroundings: things, services, light, people, information } \\
\text { accessed by the user); -Personal context ( the mental and physical information about the } \\
\text { user: mood, expertise, disabilities, weight); -Social context (friends, relatives, colleagues); } \\
\text {-Task context (user's goals, tasks, activities, etc.); -Spatio-temporal context (time, location, } \\
\text { movement); }\end{array}$ \\
\hline & & {$[43]$} & $\begin{array}{l}\text {-Internal context (user state, experience, user goals, tasks, current projects, status, to-do } \\
\text { items, personal events, user's cognitive state, user's emotional state and physical state (e.g., } \\
\text { position)); } \\
\text {-External context (temperature, time, location, people, devices, etc.); }\end{array}$ \\
\hline & & {$[44]$} & $\begin{array}{l}\text { Active context vs. Passive context containing: } \\
\text {-Computing context (network connectivity, communication costs, communication } \\
\text { bandwidth, printers, displays, workstations, etc.); -User context (user's profile, location, } \\
\text { people nearby, social situation); -Physical context (lighting, noise levels, traffic conditions, } \\
\text { temperature); } \\
\text {-Time context (time of a day, week, month, and season of the year); }\end{array}$ \\
\hline & $\begin{array}{l}\text { Mobile active } \\
\text { map service }\end{array}$ & {$[32]$} & $\begin{array}{l}\text {-Location; -Time; -People; -Objects (printers, terminals, workstations, etc.); } \\
\text {-Services (location-based services); }\end{array}$ \\
\hline \multirow[t]{3}{*}{$\begin{array}{l}\text { Context-aware } \\
\text { mobile mapping }\end{array}$} & $\begin{array}{l}\text { Mobile } \\
\text { map-based } \\
\text { spatial } \\
\text { navigation }\end{array}$ & {$[22]$} & $\begin{array}{l}\text {-Computing system context (display size, network connectivity, communication costs and } \\
\text { bandwidth, nearby resources (printers, displays), etc.); -User context (user's profile and } \\
\text { tasks); } \\
\text {-Social context (people nearby); -Cultural context (characters, date and time formats); } \\
\text {-Physical context (physical surroundings [Lighting, temperature, weather conditions, noise } \\
\text { levels], location, orientation); -Time context (time of day, week, season of year); -History } \\
\text { context (spatial navigation history); }\end{array}$ \\
\hline & $\begin{array}{l}\text { Context-aware } \\
\text { LBS }\end{array}$ & {$[33]$} & $\begin{array}{l}\text {-User preferences (dietary restriction, range of price, and acceptable restaurant rating); } \\
\text {-User context (location, available time, and privacy requirements); Environmental context } \\
\text { (e.g., time, weather, other user reviews, and current traffic); -Database-specific context } \\
\text { (e.g., for a restaurant, considering current waiting line, opening status, rating, and change of } \\
\text { menu); }\end{array}$ \\
\hline & & $\begin{array}{l}\text { [29] Cited } \\
\text { by [30] }\end{array}$ & -Mobile context; -Mobile workers; -Mobile technologies; -Mobile tasks; \\
\hline Mobile work & $\begin{array}{l}\text { Any mobile } \\
\text { work }\end{array}$ & {$[30]$} & $\begin{array}{l}\text {-Task context (interactions with the system, tasks related to the work); -Social context } \\
\text { (people, work community, culture); -Infrastructural context (technologies, network } \\
\text { connections, device, system, service ecosystems); -Spatial context (place, location, } \\
\text { temperature, noise, lighting, furniture); -Temporal context (schedules, deadlines, place of } \\
\text { work, (ir)regularity, planned/unplanned, day time or week); }\end{array}$ \\
\hline User experience & $\begin{array}{l}\text { Any mobile } \\
\text { work }\end{array}$ & [45] & $\begin{array}{l}\text {-User (values, emotions, expectations, prior experiences, physical characteristics, motor } \\
\text { functions, personality, motivation, skills, age, etc.); -Social factors (time pressure, pressure } \\
\text { of success and fail, explicit and implicit requirements, etc.); -Culutal factors (sex, fashion, } \\
\text { habits, norms, language, symbols, religion, etc.); -Context of use (time, place, } \\
\text { accompanying persons, temperature, etc.); } \\
\text {-Product/Device (usability, functions, size, weight, language, symbols, aesthetic } \\
\text { characteristics, usefulness, reputation, adaptivity, mobility); }\end{array}$ \\
\hline
\end{tabular}




\section{Continued}

$$
\begin{array}{ll}
\text { User experience } & \begin{array}{l}
\text { Mobile web } \\
\text { browsing }
\end{array}
\end{array}
$$

Spatial cognition Any activity

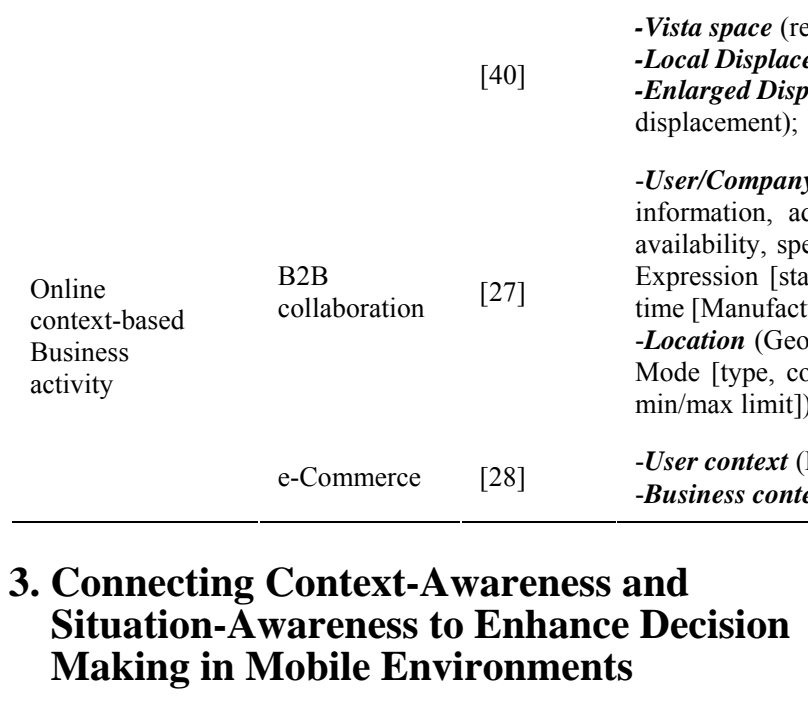

From an external empirical observation and analysis, mobility is a physical movement in space and time not only going far from a point, but also getting closer to another one, and involving a change of locations and surroundings during which, the mobile person can see, hear, smell or feel different elements that could affect his activities and his state of mind. Three essential features can be distinguished as being part of a mobile environment:

- The user's personal bubble or personal context, in which the decision maker acts, thinks, and tries to decode the information he/she perceives. This personal bubble can be linked to the mental body space developed by [39].

- The surrounding environment in which external things change while the decision maker is in motion. This area may vary from closest to farthest areas surrounding the user.

- A set of natural (eyes, ears, nose, gestures, touch, etc.) or artificial (GUI, mouse, keyboard, sensors, etc.) interfaces which allow an exchange of information between the decision maker and his surroundings.

This empirical structure of mobile environment we determine can be, somehow, mapped with the mental spaces identified by [39]. Indeed, as reviewed in the "related works" section, [39] states that, from an internal perception, human beings divide mobile environments into three hierarchical spaces which are: 1) the body space; 2) the space around the body; and 3) the navigation space. Therefore, the external personal bubble may be linked to the mental body space, while the space around the body and the navigation space can be considered as the mental representation of the surrounding environment. This mapping might be also made with the vista space and the local displacement space proposed by [40], but only if the current environment is the decision maker's life space.

The set of natural interfaces (human senses) identified above are those that acquire events occurring in the surroundings and provide to the user, his/her raw situation awareness, while the set of artificial interfaces may be exploited by context-aware applications to acquire, filter and process these events in order to enhance the user's situation awareness and lead him to well informed decisions.

Indeed, context-awareness, by enabling applications to capture and process contextual information, can help mobile decision makers to collect, exploit and build their decisions on more accurate and precise information about their business context than they would expect since some contextual information might have escaped human attention or ask for more cognition and effort. For example, by being informed almost in real-time by context-awareservices of available services within a given area of interest (AOI) and within a planned time interval, and by getting alerted about important youth events within this AOI from social networks and web sensors, and by gaining summarized and substantial data about youth habits and consumptions during these events, a mobile sales- 
man could plan effectively his sales-journey and would more likely sell more. Simply put, context awareness helps minimize user interactions and make applications more intuitive and intelligent in order to improve their usability in different contexts. Thereby context awareness can support decision makers to get well informed of their context, be aware to their business situation and lead them to informed decisions.

Besides, it is worth to highlight that if most work on contextual information awareness mainly considers the problem of applications' context-awareness, it surpriseingly seems to ignore the fact that the user is also aware of his context, being supported or not by a context-aware application. We argue that the user sensibility to the context (known as situation awareness) should also be considered.

In fact, while context-awareness is the ability of applications to sense some contextual information (e.g. the user position, the surrounding temperature, etc.), situation awareness is the cognitive process by which the decision maker learns, understands and builds a representation of his current decision situation (context + problem to solve). Several authors such as [46] and [47] reminded that the concept of situation awareness comes from the air force and it relates to the pilot's knowledge about the aircraft and his flying environment. In short, "situation awareness is about knowing what is going on around the decision maker" and "richer Situation Awareness is more likely to lead to good decisions and then to good performance" [48,49].

Accordingly, context-aware applications could lead to better decisions and better performance if they are able to improve the raw situation awareness of the decision maker by sensing, collecting, filtering, processing, and supplying relevant contextual information in accordance with the user's requirements and goals, especially in a mobile context where workspaces are dynamic and change so often. This connection between applications' context awareness and the decision maker's situation awareness and the improvement that can stems from it is illustrated in Figure 1. This diagram shows that when the contextual information is intelligibly processed and presented on a mobile device, it can help the decision maker to be more aware of his contextual situation and drive him to well-informed decisions.

Furthermore, the user cognition (the way he thinks and feels) should be provided to the context-aware application to make it more adapted or helpful to him. For example, by knowing that the user is agoraphobic or claustrophobic, an application could alert him about unfamiliar public/places to go far from or narrow spaces (e.g. elevator) to avoid.

Moreover, since mood (e.g. optimistic, pessimistic, trustful, suspicious, etc.) may impact business performance [50,51], a mobile context-based application, by capturing the user's mood of the day (e.g. anger, impatience, etc.) via mood aware applications and devicese.g. "microphones, cameras, heart and body monitors" [52], etc. - might propose to the user, routes which avoid rush places, suggest him to postpone crucial meetings, draw his attention on decisions he takes while in bad mood, etc. A foreman may also use such mood-awareness analysis to assign the right employee to the right task for the right client to serve.

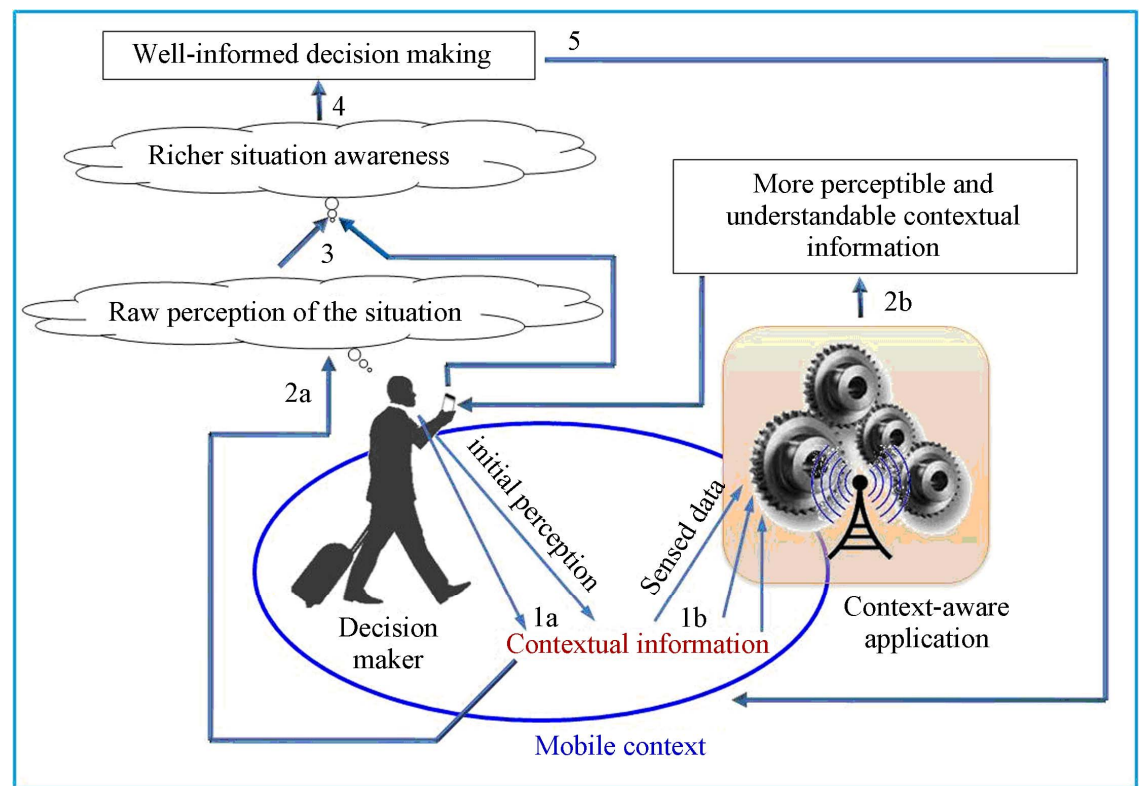

Figure 1. Simplified model of connection between the applications' context awareness and the decision makers' situation awareness. 
We think that a cognition-compliant model of context should then be envisage and should match the hierarchical organization of mobile environments. For this reason, the notions of space and time from mobility, user's bubble and surrounding environment from mobile environments, and hierarchical cognitive spaces from human perception of space will be exploited to organize, identify, discuss and structure relevant contextual information and dimensions for the mobile GeoBI context model we propose in next section.

\section{Relevant Contextual Information and Suitable Model for a Mobile GeoBI Context}

When dealing with mobile context, time and location (space) appear as the primary notions that should be accounted (cf. major dimensions in the literature-Table 1) since mobility and mobile environments are obviously time-dependent and location-based (see Section 3). Stated in the literature as context dimensions designated by time-context (or temporal context) and location-context (or spatial context), they are usually addressed as common contextual information. To our opinion, these notions involve more specific contextual impacts that deserve further discussions: 1) time should not be considered only as a context but also as a variable dimension which potentially affects all other contextual information and context dimensions; 2) since Mobile GeoBI context is location-based, it should be considered as related to the location the mobile business professional is located in, namely the local context (e.g. Quebec city business context), or as related to a remote location, namely a remote context (e.g. Wall Street) whose business activities may influence the local context. The way these local and remote contexts can share information has also to be handled through a suitable and optimized mobile GeoBI context model we propose.

To ease its comprehension and underline its multilevel hierarchical structure, we will expose and build it step by step in this part of the paper. We will thus expose step by step: 1) the relevance and specificity of time; 2) the relevance of location and the problematic of context sharing between a local GeoBI context and remote contexts; 3) the different levels of a mobile GeoBI context; 4) the major dimensions of a mobile GeoBI context; and 5) the key elements composing each dimension of a mobile GeoBI context.

\subsection{Relevance and Specificity of Time Dimension in Context}

Several authors have identified the temporal context (also called time context) as a relevant contextual key element but they do not agree when trying to explain the concepts it refers to. Indeed, while [20] and [22] stated that time context is about the time of a day, the week, the month or the season of year, etc., others researchers such as [53], [42], and [34], only consider time (date-hour, the current time or the system clock time) as being the relevant item of a temporal context. Contrary to all other authors, [31] argued that "time alone does not directly affect the user experience. If it is a winter night, it is likely to affect temperature, lighting, social context, user's mental resources and needs, but not directly user experience. The relevant contextual information is not in the time itself, but in the attributes the time affects".

We consider like [31], that time-dimension may potentially affect all other contexts and dimensions elements so that it has to be handled as a specific dimension different from other contexts. Moreover, as stated by [53], retrieving time itself (e.g. date-hour-second) and periods (starting time - ending time) is also necessary and sufficient for knowing the time or the period during which events took place in the context, in which order, etc. In addition, with a given date, it is possible to determine the corresponding weekday, month, season, etc. Time is also indispensable not only for identifying repetitive phenomena or for predicting future events, etc., but also for context versioning (chronological status of the same context) and for context historization (archiving ancient contexts into non-modifiable state for later use).

Both context versioning and context historization can be defined based on some attributes or criteria. For example, Figure 2(a) presents an activity-based context versioning and shows how the same context may evolve over the time; Figure 2(b) provides a case of context historization based on the visited locations so that ancient contexts of the same location might be recovered and compared more easily.

To highlight the starting and ending time on contextual elements affected by time, the temporal dimension is represented by a temporal pictogram (ð) introduced by [54] for indicating time-dependent attributes. A mobile GeoBI context itself is time-dependent and all its dimensions (see Table 2) are potentially time-dependent as illustrated below by the UML model proposed in Figures 3-5.

In addition to being time-dependent, a mobile GeoBI context is also location-based and may share contextual information with a remote context located in another location. This point is discussed in the next section.

\subsection{Relevance of Location-Dimension and Problematic of Context Sharing}

Location is naturally a relevant contextual dimension as mobility in general and professional mobility in particular, is usually justified by the user's need to experiment a 


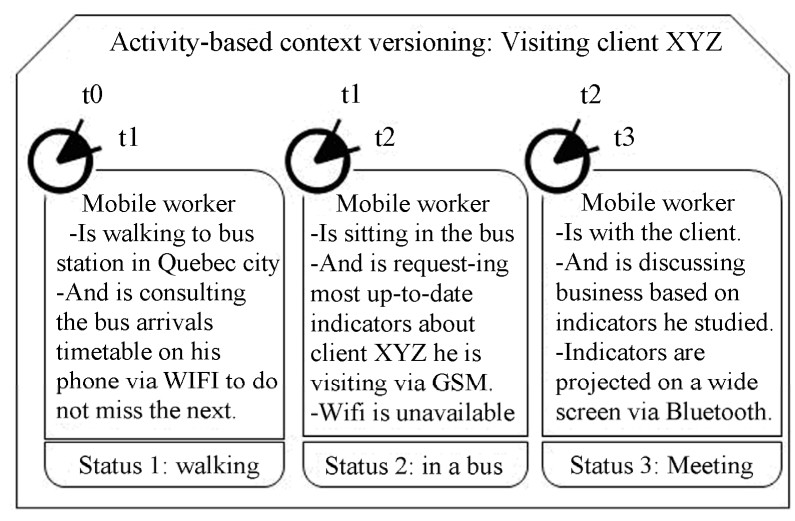

(a)

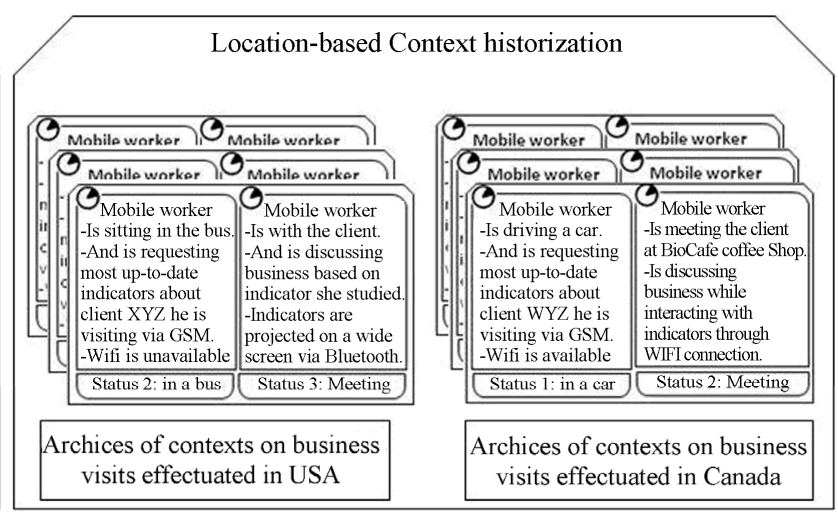

(b)

Figure 2. (a) Example of context versioning; (b) Example of context historization.

Table 2. Relevant dimensions for a mobile GeoBI context.

\begin{tabular}{|c|c|c|c|c|}
\hline \multirow{2}{*}{ Context Level } & \multirow{2}{*}{ Dimen-sions } & \multirow{2}{*}{ Description } & \multicolumn{2}{|l|}{ Relevance for } \\
\hline & & & Mobility & BI \\
\hline \multirow{4}{*}{ Personal context } & Goal & $\begin{array}{l}\text { The mobile person's goal, agenda, needs, } \\
\text { intentions or interests in what he is doing or } \\
\text { intend to do. }\end{array}$ & \multicolumn{2}{|c|}{$\begin{array}{l}++ \\
\text { Pertinent to assist the user to reach the expected task. For } \\
\text { example, detecting the user's intention to visit the closest } \\
\text { client by sensing his current position and direction, and } \\
\text { then propose him the most rapid route and display the } \\
\text { most up to date and critical indicators about this client. }\end{array}$} \\
\hline & Identity & $\begin{array}{l}\text { The person's role and identity such as his } \\
\text { civil, professional or use profile. }\end{array}$ & $\begin{array}{l}+ \\
\text { Moderately relevant for } \\
\text { accessing spatial } \\
\text { navigation support } \\
\text { applications. }\end{array}$ & $\begin{array}{l}++ \\
\text { Strongly relevant for } \\
\text { supplying right information } \\
\text { to the right decision maker } \\
\text { based on his identity. }\end{array}$ \\
\hline & Cognition & $\begin{array}{l}\text { The way the person thinks, acts or feels. In } \\
\text { short, the person's psychological profile } \\
\text { (mood, behavior) and preferences (like/ } \\
\text { dislike). }\end{array}$ & $\begin{array}{l}++ \\
\text { Relevant to know for } \\
\text { example where the user } \\
\text { should not go (e.g. } \\
\text { agoraphobic or } \\
\text { claustrophobic), or } \\
\text { would like to visit. }\end{array}$ & $\begin{array}{l}++ \\
\text { Relevant for handling in } \\
\text { which ways the mobile } \\
\text { worker might be "advised" } \\
\text { and assisted in his } \\
\text { activities. }\end{array}$ \\
\hline & Tasks & $\begin{array}{l}\text { Tasks carried out. These can be Mobility } \\
\text { tasks (e.g. driving, walking, etc.), BI tasks } \\
\text { (requesting decisional data, meetings), } \\
\text { Communication tasks (calling, messaging, } \\
\text { etc.), Other tasks (e.g. carrying a weight, } \\
\text { painting a wall, etc.). }\end{array}$ & $\begin{array}{l}++ \\
\text { Relevant for Mobility } \\
\text { tasks. }\end{array}$ & $\begin{array}{l}++ \\
\text { Relevant for } \boldsymbol{B I} \text { tasks. }\end{array}$ \\
\hline \multirow{2}{*}{$\begin{array}{l}\text { Surrounding context } \\
\text { (including ambient } \\
\text { context) }\end{array}$} & $\begin{array}{l}\text { Business } \\
\text { context }\end{array}$ & $\begin{array}{l}\text { All information about business strategy, } \\
\text { activities, resources, markets, competition } \\
\text { and partnership. In short, all about business } \\
\text { facts and problems: metrics, indicators, } \\
\text { KPIs, etc. }\end{array}$ & $\begin{array}{l}\text { Not really relevant for } \\
\text { mobility. }\end{array}$ & $\begin{array}{l}++ \\
\text { Of course, highly relevant } \\
\text { for business intelligence } \\
\text { support. }\end{array}$ \\
\hline & Social context & $\begin{array}{l}\text { Social context is not only about social } \\
\text { networks, but also about culture, power } \\
\text { systems (i.e. politics) and resources } \\
\text { management (economy). In short, it's } \\
\text { about social organizations of humans } \\
\text { and resources. }\end{array}$ & $\begin{array}{l}+ \\
\text { Moderately relevant for } \\
\text { asking location } \\
\text { information or } \\
\text { discovering POIs of a } \\
\text { society. }\end{array}$ & $\begin{array}{l}++ \\
\text { Strongly pertinent for } \\
\text { understanding and dealing } \\
\text { with social groups, local } \\
\text { culture, resources and } \\
\text { institutions. }\end{array}$ \\
\hline
\end{tabular}




\section{Continued}

\begin{tabular}{|c|c|c|c|c|}
\hline \multirow[b]{2}{*}{$\begin{array}{l}\text { Surrounding context } \\
\text { (including ambient } \\
\text { context) }\end{array}$} & $\begin{array}{l}\text { Environmental } \\
\text { context }\end{array}$ & $\begin{array}{l}\text { Refers to environmental conditions (seasons, } \\
\text { weather, noise) and services (transportation, } \\
\text { banking, hotels booking, etc.) available in } \\
\text { this environment. }\end{array}$ & \multicolumn{2}{|c|}{$\begin{array}{l}++ \\
\text { Strongly relevant for adapting activities (Mobility and } \\
\text { BI tasks) to environmental conditions and available } \\
\text { services. }\end{array}$} \\
\hline & Spatial context & $\begin{array}{l}\text { Refers to spatial localization of pertinent } \\
\text { objects located in the mobile environment } \\
\text { including persons, natural geography objects } \\
\text { (e.g. lands, vegetation, water, natural } \\
\text { resources, etc.) and human geography objects } \\
\text { (roads, places, POIs, infrastructures, etc.). }\end{array}$ & $\begin{array}{l}++ \\
\text { Strongly relevant for } \\
\text { spatial navigation. }\end{array}$ & $\begin{array}{l}++ \\
\text { Strongly relevant for } \\
\text { locating companies, } \\
\text { customers and for delivery } \\
\text { issues (costs, delays, etc.). }\end{array}$ \\
\hline $\begin{array}{l}\text { All contexts and } \\
\text { dimensions above }\end{array}$ & $\begin{array}{l}\text { Temporal } \\
\text { dimension }\end{array}$ & $\begin{array}{l}\text { Refers to the time or the period during which } \\
\text { tasks are carried out, events occur, resources } \\
\text { are available, etc. For us, the temporal } \\
\text { dimension is specific and affects all context } \\
\text { and dimensions we treated above. This } \\
\text { specificity is explained in Section 5.4. }\end{array}$ & $\begin{array}{l}++ \\
\text { Relevant for journey } \\
\text { duration, transportation } \\
\text { means availability time, } \\
\text { etc. }\end{array}$ & $\begin{array}{l}++ \\
\text { Pertinent for monitoring } \\
\text { business evolution over } \\
\text { time, timeliness, etc. }\end{array}$ \\
\hline
\end{tabular}

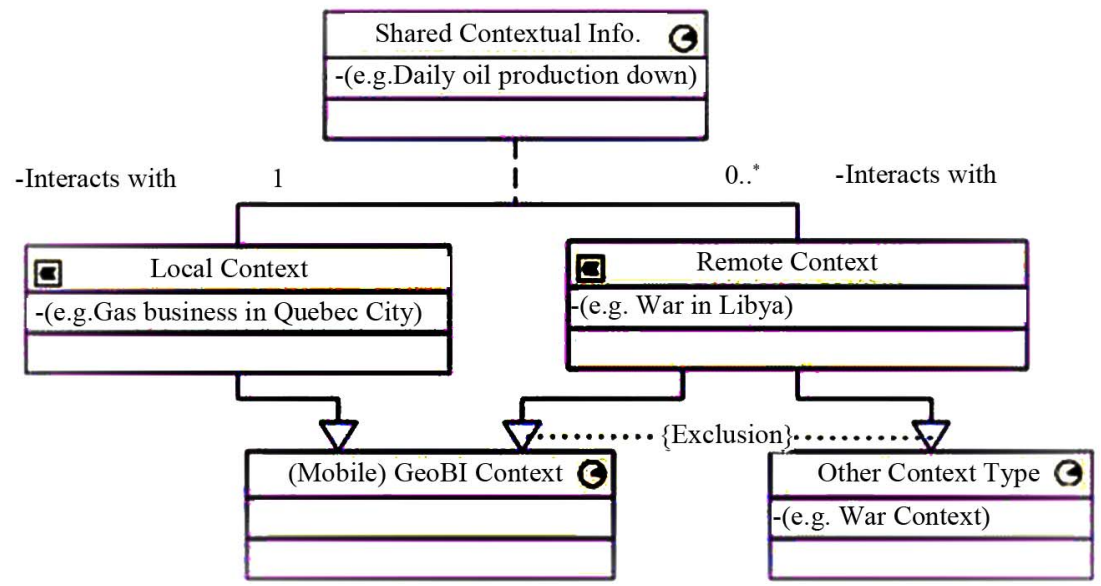

Figure 3. Optimized context-sharing model.

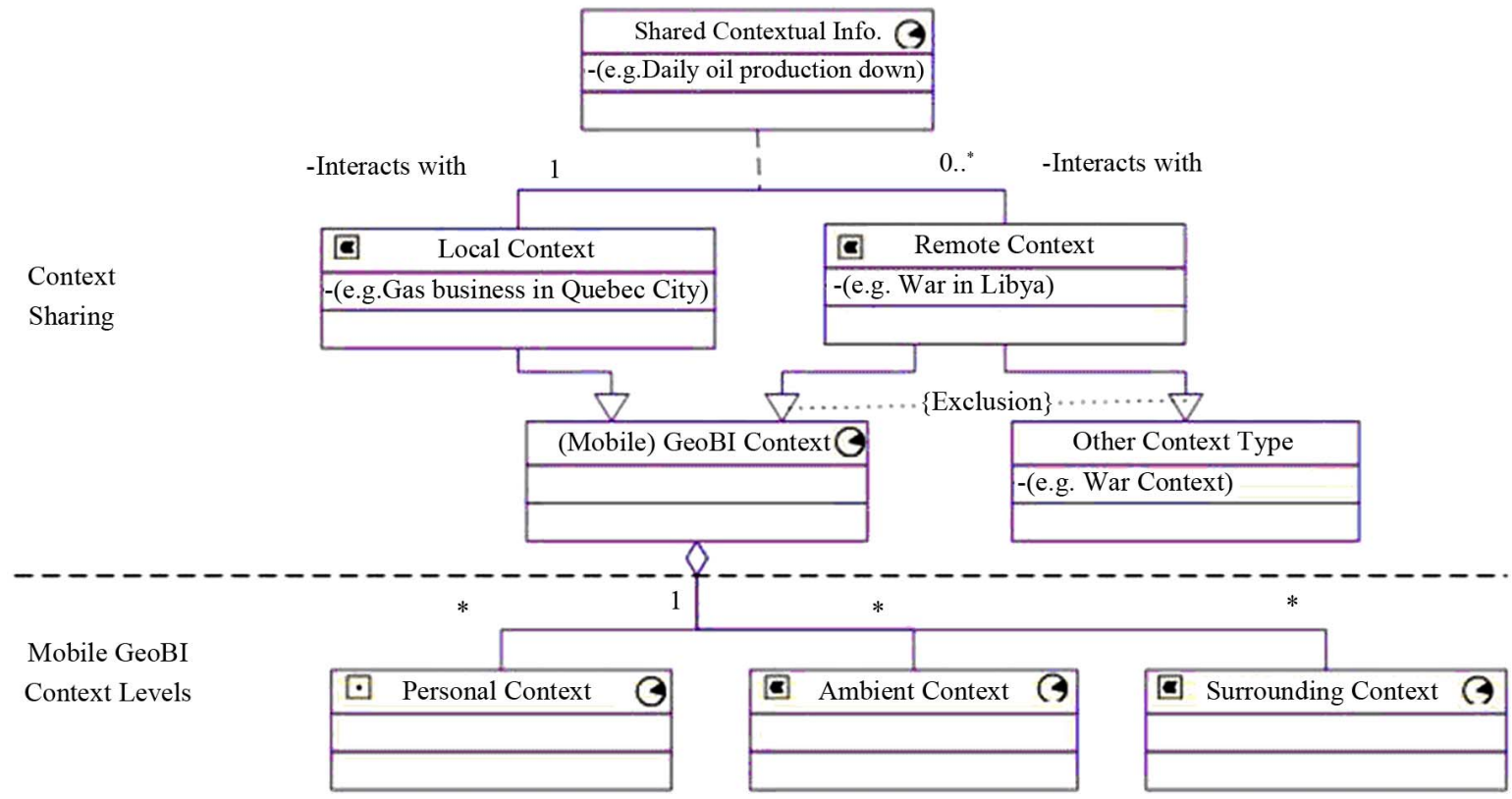

Figure 4. Modeling mobile GeoBI context levels in accordance with context-sharing. 


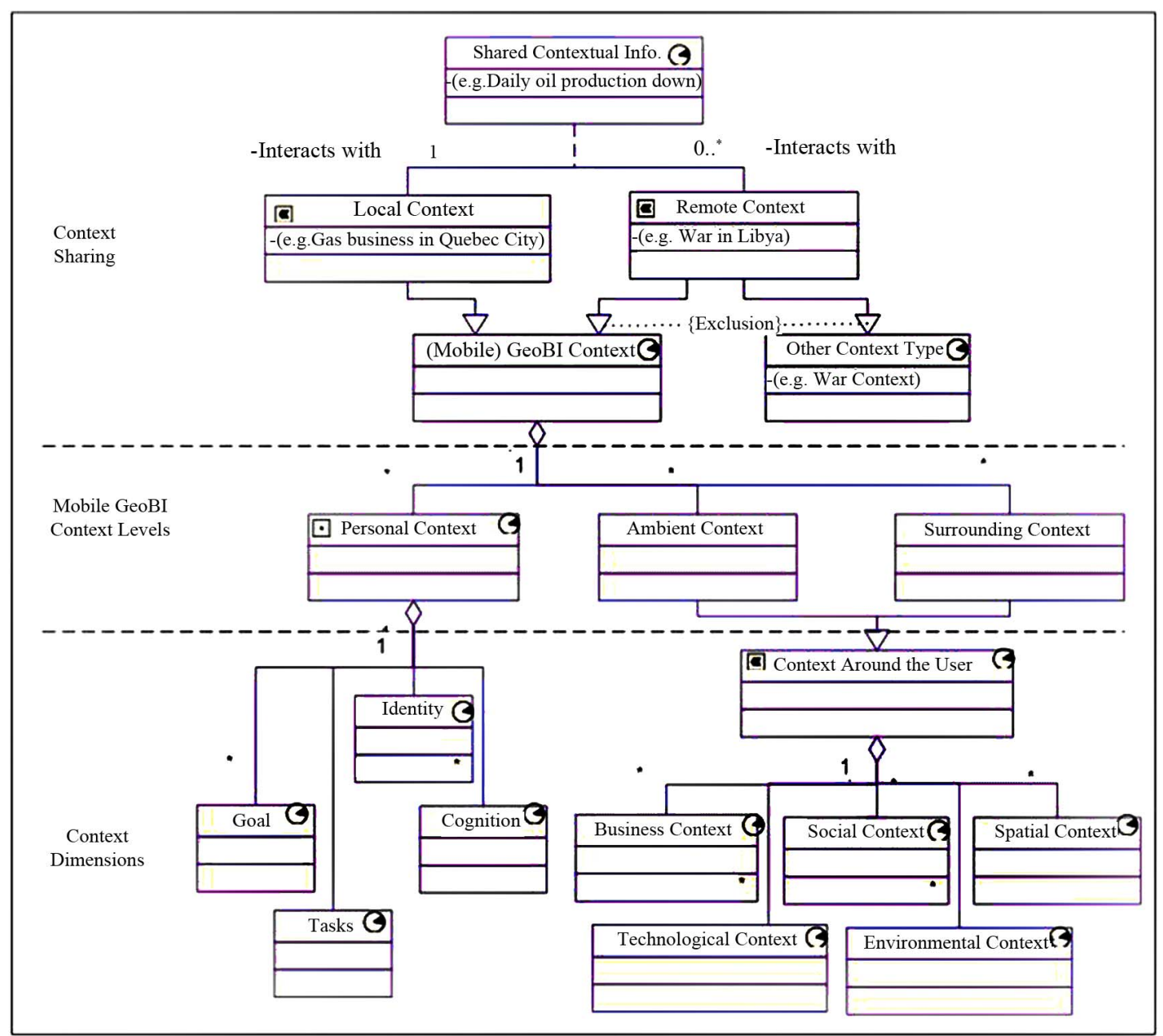

Figure 5. Multilevel mobile GeoBI context model (GeoMoBICoMod) for context-sharing and structuring (top level model).

physical proximity to resources [17] such as meeting persons (customers, suppliers, etc.), scrutinizing more closely a phenomenon (pollution, traffic, sales on the field, etc.) or visiting POIs (Points Of Interest), etc. in a given location which may affect the user, ease or complicate his business activities, etc.

In the scope of mobile GeoBI context, this location dimension will be designated in the rest of the paper as "(geo) spatial context", and will refer to the spatial localization of relevant features located in the mobile environment including persons, natural geography features (e.g. lands, vegetation, water, natural resources, etc.) and human geography objects (roads, places, POIs, infrastructures, etc.). This (geo) spatial context is strongly relevant for supporting the decision maker's spatial navigation (mobility support) as well as for locating companies, customers, delivery issues (costs, delays, etc.), etc. for BI support. To specify that these objects are geo-localized, we will use spatial pictograms (ç,Đ, $\hat{U})$ introduced by [54] to indicate their geometry (point, line, and polygon) and by the way, their localization coordi- nates.

By referring to the mobile environment around the decision maker's position, a mobile GeoBI context is by definition a local (spatially limited) context dealing with contextual information present in this local context of the mobile business man. As nobody is completely cut off from the world, especially in nowadays global world, a local business contextual information (e.g. gas price in Quebec City) may be affected by a remote context whatever the business context (e.g. wall street stock exchange) or any other context (e.g. war in Libya) is. So, a mobile GeoBI context is about a local context potentially sharing information with remote contexts.

This problematic of context sharing may be handled through different ways resulting in location-based contextualization of contextual information to better handle influences and information-sharing between local and remote contexts.

A first approach could consist in considering that local context as well as remote contexts are parts of a final context, and that this final context should result from the 
combination (composition operations) of the local context and remote contexts. This is the approach adopted by [34] and illustrated in Figure 6.

The limits of this approach reside in the fact that if we know well the structure and content of the local context, we do not really always have a wide knowledge of the remote context. The remote context could be very similar to the local context (e.g. GeoBI context), or totally different (e.g. War context) and its content may not be accessible at all except for the shared contextual information.

The second approach we propose to optimize and palliate the limits of the first one, considers that the local business context and remote contexts are separate contexts which interact and share contextual information with each other. This approach provides a flexible solution to handle shared information and focuses mainly on shared information rather than on the entire remote context which is not always well known. This approach is depicted by the UML model illustrated in Figure 3. It is an adaptation from [34]. Some classes have been provided with comprehensive but non-formal attributes just to help in integrating the examples of local and remote contexts given in the previous paragraphs; and for simplification sake, we chose to add an exclusive constraint to underline that a given remote context cannot encapsulate a GeoBI context type with a different context type.

This model is the first level (the sharing level) of the multi-level mobile GeoBI model we are building and is intended to map human multi-level perception of mobile environments. As designed in the model (Figure 3), the local context as well as the remote context can be mobile GeoBI contexts. The polygon pictogram $(\hat{\mathrm{U}})$ has been added in the left side of local and remote contexts to define them as limited and geo-located. Relevant contextual information composing these contexts, in addition to time and location, will be identified and organized in Sections 4.3 and 4.4 in a way that match the hierarchical structure of mobile environment and human perception of space presented in Section 3.

\subsection{Relevant Hierarchical Levels of a Mobile GeoBI Context}

Integrating the hierarchical cognitive spaces (body space,

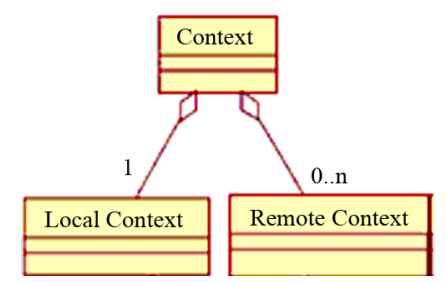

Figure 6. Combination of local and remote contexts to the same context by [34]. space around the body, navigation space) and main elements distinguishable in the environment (the user's bubble, the surrounding environment, the set of natural and artificial interfaces) identified from internal and external scrutiny of mobile environments (Section 3), we propose three hierarchical levels of context composing a mobile GeoBI context as follows:

- The personal context which is about any contextual information in relation with the user such as his profiles, goals, tasks, etc. A fair number of mobile applications could be classified as personal context-based applications given that they are only aware of the user's profile (username, password, access rights, etc.).

- The ambient context that is related to the immediate environment around the user in which things can be more accurately sensed by the user (via human interfaces as eyes, ears, skin, nose, etc.) as well as by applications (via computer interfaces such as sensors, e.g. thermometer, GPS, etc.). The ambient context is a subset of the surrounding context.

- The surrounding context which potentially covers the whole surrounding environment. Its limits may vary from a district to a city or country perimeter. More generally, a possibility should be offered to the user to spatially draw the borders of this context. For example, by drawing his area of interest (AOI) around his position (or not), the user could be able to request or receive business information related to this area (and outside it). An example of such a request may be: "Which are the fast selling products versus the best profitable products per store in a radius of $5 \mathrm{~km}$ around my current geographic position during the last two months?"

Organizing the mobile GeoBI context into these hierarchical levels of context is useful and helpful as it is consistent with existing hierarchical systems usually involved in mobility such as wireless IT networks which spans from personal area networks (PAN) to world area networks (WAN), mobile mapping (zooming levels), mobile cognition and mobility levels. Figure 7 illustrates this parallel among mobility, spatial cognition, mobile mapping, and network technologies.

This organization of mobile context also helps handling the fact that in the context of business intelligence, a local (mobile) context may be affected by, interact or share contextual information with a remote context as previously presented. Rather than melting all contextual information in the same and unique level while it is not, this hierarchical structure conceptually provides a right way to better organize contextual information by putting the right information at the right context level. For the mobile context-aware application and for the mobile user, it will be also a straightforward approach (without additional computing time) to know if it or he/she is dealing 


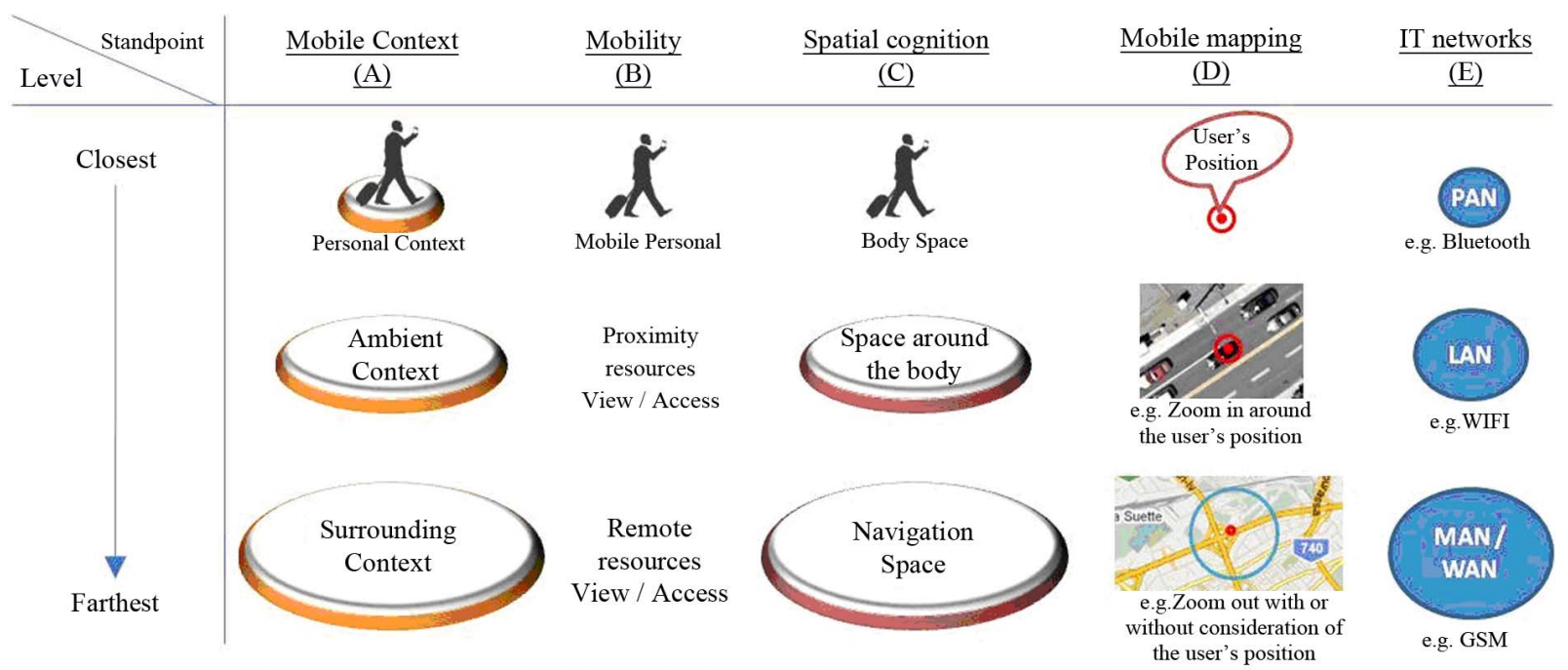

Figure 7. Hierarchical levels (of granularity) of mobile context in parallel with other standpoints.

with local or remote information, and if that information is related to a mobile person, the immediate environment or the distant surrounding environment.

Figure 4 presents how these hierarchical mobile GeoBI context levels can be modeled and integrated with the first level (context-sharing level) of the multi-levels mobile GeoBI context model we are constructing section after section We have chosen to geo-localize the personal context as a point which represents the current position of the concerned person, but this may vary depending on the targeted usage: e.g. representing the space occupied by the person's body (e.g.: shoulder width X chest thickness) rather than his position.

Now, for each level of context (personal, ambient, surrounding), relevant contextual information and dimensions have to be identified and analyzed in the purpose of being sensed and/or managed by context-aware mobile GeoBI applications.

\subsection{Relevant Context Dimensions and Basic Model for Mobile GeoBI Context}

Based on Business Intelligence activity, mobile environments nature and the existing work on contexts listed previously, the following dimensions (Table 2) have been considered as relevant for a GeoBI context-aware application. They are potentially able to fully support a mobile decision maker carrying out tasks in a mobile business intelligence context. To remain compatible with human perception of space, these dimensions will lean on the three hierarchical context previously identified: personal context, ambient context, and surrounding context.

Each context has been explored through its main meaningful contextual data grouped into dimensions. We consider that a dimension may be in turn a context encompassing other dimensions (e.g. technological context is related to the technological dimension of the surrounding context, and should be composed of other dimensions, such as data, devices, interactions or networks context, etc.). The dimensions have been selected based on their relevance for mobility and/or for Business Intelligence activity.

By appending these context dimensions to each context level modeled in the previous part of the model (Figure 7) we are assembling since the beginning, we complete here, our proposal of a multilevel mobile GeoBI context model for context-sharing and structuring (Figure 5). It depicts a hierarchical structure of the mobile GeoBI model in which, context levels are rendered into classes having an aggregation of dimensions. As ambient and surrounding contexts have the same dimensions, they aggregate the related dimensions classes by inheriting an abstract class named "Context around the user".

Note that ambient and surrounding contexts share the same dimensions. Their difference resides in their scope. Indeed, ambient context is a restriction of surrounding context to a given area of Interest (AOI), which leads to a kind of projection (limitation) of the dimensions content inside this AOI. Conversely, a surrounding context is somehow, an extension of ambient context to a wider AOI. Also note that neither the spatial dimension nor the others have a spatial pictogram specifying the need to geo-localize them because they will be mapped (i.e. clipped) to the spatial extent of the context around the user (ambient context and surrounding context). Then, only detailed contextual information (e.g. devices-mobile or not-for technological context, social groups for social context, companies for business context, roads for spatial context, etc.) belonging to these dimensions need to be geo-localized. 


\subsection{Advantages and Innovations of the Proposed Model}

The proposed multi-level mobile GeoBI context model is a first contribution of our ongoing research on context-based mobile GeoBI. Its advantages reside in the fact that it:

- Provides a right way to better organize contextual information by putting the right information at the right context level rather than melting all contextual information in the same and unique level while it is not;

- Matches human perception of space which typecast contextual information into closest, near or remote elements. This matching has the advantage to ease the future presentation of processed contextual information and make it appear as natural to the user;

- Provides a flexible solution to handle information shared between local and remote contexts and focuses mainly on shared information rather than on the entire remote context which is not always well known;

- Is appropriate to the hierarchical data storing, grouping and aggregating usually implemented by BI systems. That could ease a future coupling of this model with BI data structures in order to provide mobile users business professionals with appropriate contextual analytics.

The proposed model also provides some innovations residing in the fact that it is explicitly:

- Geospatial-enabled,

- Time-dependent,

- Easy to extend by extending a given dimension or by plotting à new one, from top to bottom,

- And it adopts a location-based contextualization of contextual information to better handle influences and information-sharing between local and remote contexts.

This final version constitutes a top-level model and a basic framework which could be extended with detailed elements. Next section provides for researchers and practitioners needing to extend this model, a wide and somehow complete inventory of relevant detailed contextual information organized by context level and context dimension.

\subsection{Detailed Relevant Contextual Information for a Mobile GeoBI Context}

To be context-aware, mobile GeoBI applications will need to sense (with sensors) or retrieve (e.g. through user inputs) detailed precise and accurate information (e.g. user position, his office address) that can be turned into data usable by an IT system. Then, after determining and modeling the main concepts involved with mobile GeoBI context, we have inventoried (mainly based on the detailed review conducted in Section 2.3-see Table 1) some detailed contextual information which may help extend, complete and feed these concepts with more detailed classes and attributes. Identified elements have been analyzed as relevant for business intelligence activity in mobility and have then been organized by context level and context dimension.

\subsubsection{Relevant Contextual Information in Personal Context}

Personal context is about any relevant contextual information regarding the user which might affect the behaveior of an application. Table 3 exposes some elements which may help characterize a mobile GeoBI context. Personal context is intended to bring answers to questions related to the mobile worker, namely:

- "Who is he?" i.e. his identity (e.g. civil profile, physiological profile, social profile, professional profile, etc.);

- "What does he need or intend to do?" i.e. his goals (intentions, needs, interests, agenda...);

- "How does he proceed to think of, to solve a problem/ How does he feel things, etc.?" i.e. his cognition (e.g. psychological profile (mood, temperament, feelings), preferences, etc.);

- "What is he doing/what does he have to do?" i.e. his tasks which can be grouped into mobility tasks (e.g. walking, driving, etc.), communication tasks (e.g. calling, messaging, tchating, twitting, etc.), BI tasks (meetings, consulting/requesting decisional data), physical work tasks (e.g. carrying a box of products), etc.

\subsubsection{Relevant Contextual Information in Context around the User}

Similarly to the personal context, the context around the user (surrounding and ambient contexts) context has been designed based on answers to some main questions related to contextual issues which usually are: when (temporal context which is actually related to all levels of context)? Where (spatial context)? In which environmental conditions (environmental context) and in which human environment (social context) events are happening?

Instead of what is usually stated [55], social context is not only about Culture or Social network (social groups and their relationships), but it is also about Power (authorities) and Resources, and their distribution between social groups and institutions. Social context brings then an overview of the social organization of a given society.

As far as business intelligence is concerned, new contexts need to be introduced to take into account business and technological aspects providing answers to the following questions: "what is concerned?" Business Intelligence (Business Context); and "how to achieve that?" By 
Table 3. Relevant contextual information for a mobile GeoBI context at the personal level.

\begin{tabular}{|c|c|c|}
\hline Context level & $\begin{array}{l}\text { Context } \\
\text { dimensions }\end{array}$ & $\begin{array}{l}\text { Relevant contextual information } \\
\text { (Key elements and details) }\end{array}$ \\
\hline \multirow{14}{*}{$\begin{array}{l}\text { Personal } \\
\text { context }\end{array}$} & \multirow{5}{*}{ Identity } & Civil Profile (Name, Address, Marital Status, Languages, etc.). \\
\hline & & Professional Profile (Diploma, Skills, Experience, Performance, Role, Results, etc.). \\
\hline & & $\begin{array}{l}\text { Physiological Profile (Body Description [Weight, Height, Skin Color, Hair color, Eye Color]; Body Disabilities } \\
\text { [motor, visual, hearing, etc.]; Genetics [DNA, Blood Group, Rhesus, Fingerprint, etc.]; Health [diseases, allergies, } \\
\text { etc.]). }\end{array}$ \\
\hline & & Social Profile (Family, Community, Association, Friends, Relatives, Life Style, etc.). \\
\hline & & Use(r) Profile (Login, Password, Rights, etc.). \\
\hline & \multirow{3}{*}{ Goal } & $\begin{array}{l}\text { Needs/Intentions (Business needs to fulfill or objectives to reach at personal level. E.g. Need to register } 10 \text { new } \\
\text { customers today!). }\end{array}$ \\
\hline & & $\begin{array}{l}\text { Interest (Business centers of interest. E.g. selling innovative products, prospecting customers, analyzing revenues } \\
\text { from delivery services, keeping informed of stocks level in the company's closest shops, etc.). }\end{array}$ \\
\hline & & Agenda (Planned interest or tasks. e.g. from 9 to 10 a.m. prospecting customers). \\
\hline & \multirow[b]{2}{*}{ Cognition } & Psychological Profile (Temperament, Mood, Hobby, Personality Traits, etc.). \\
\hline & & $\begin{array}{l}\text { Preferences (Indicate what the decision maker likes the most for each of his profile. E.g. Civil Profile: A perfect } \\
\text { bilingual, but prefers speaking French, etc.). }\end{array}$ \\
\hline & \multirow{4}{*}{ Tasks } & BI Tasks (Type [consulting/requesting decisional data], metrics, Qty of Data to download, Network, costs, etc.) \\
\hline & & Mobility Tasks (Type [walking, driving, etc], Duration, etc.). \\
\hline & & Communication Tasks (Type [e.g. calling, messaging, tchating, twitting, etc.]; Duration, Network, Costs, etc.). \\
\hline & & Physical Tasks (Duration, Difficulty, Distance, etc.) E.g. carrying a box of products, etc. \\
\hline
\end{tabular}

exploiting technological capabilities (Technological Context).

Based on these questions and answers, the following key elements and their detailed information have been identified as potential relevant contextual information for a mobile GeoBI context in the ambient and surrounding contexts levels (Table 4).

Thanks to these detailed contextual elements, the proposed top level model of mobile GeoBI context (above Figure 5) could be richly extended and detailed. Future work will provide researchers and practitioners with a more complete model for context-reasoning and implementation perspectives. Since this is a work in progress, the implementation of the model will then be tackled later.

\section{Conclusions and Future Work}

The requirement for high performance results in the mobile global highly competitive and technology-based business world we are in, has led to the need for business professionals to get supported by convenient mobile DSS, in order to keep ruling and monitoring their companies indicators from anywhere at any time.

This paper in its beginning has stated that such mobile DSS are nowadays mostly built on BI Systems to allow a full accounting and remote access to organizational data and analysis tools, but suffer from do not taking into ac- count the user's mobile context. The need for context-based and geospatial-enabled BI (GeoBI) applications has then been justified, and the problematic of identifying relevant contextual information to capture and to model into a way that matches BI data models and human cognition of mobile spaces has been raised. Elements of solution have been provided though out the rest of the article.

Indeed, after demonstrating that context-awareness may lead to faster and better well-informed decision making, a large inventory of relevant contextual information identified and captured by authors in the literature and intended to context-aware applications has been provided to apprehend the state of the art of existing work. From this review, and based on BI activity and mobile environments nature, we have proceeded step by step to the identification and analysis of major relevant context dimensions for mobile GeoBI contexts so that at the end, block after block, a suitable multilevel Geospatial Mobile Business Intelligence Context Model (GeoMoBICoMod) has been proposed, designed and justified.

In short, the other major contributions of this paper are:

- A highlight of the connection between contextawareness, situation-awareness and decision making in the process of decision-making;

- A distinction of time-context as a specific dimension affecting all other context elements; 
Table 4. Relevant contextual information for a mobile GeoBI context in ambient and surrounding contexts.

Context level $\quad \begin{aligned} & \text { Context } \\ & \text { dimensions }\end{aligned} \quad$ Relevant contextual information (Key elements and details)

Company ([company name, registration number, contact information, address, etc.])

Strategy (Objectives/results to reach, Business models and plans, business management processes, problem solving processes, analysis/forecasting tools and techniques [metrics, KPIs, dashboards, reports, etc.], etc.)

Business

context

Activity (Nature, Management chain [managers and teams hierarchy], Production process [rate, input, output, production time, etc.], Tasks [nature, objective, constraints, etc.], Involved resources [human resources, goods/services, financial resources, etc.], etc.)

Business Resources (turnover, cash flow, debts, goods/services, products, human resources [leaders, managers, workers, consultants, etc.], material resources [buildings, offices, machines, computing systems, etc.] etc.)

Markets (Sectors, Supply and demand, Consumers, Customers, Suppliers, Investors, Distribution networks, Stock exchange, etc.)

Competition / Partnership (Nature, rules, actors, etc.)

Hardware (computers, mobile phones, networks [wired networks, mobile networks, GNSS networks, etc.], sensors [Thermometer, Accelerometer, GPS receiver, Gyroscope, scanners, etc.], etc.)

Software (Operating systems, System oriented software [libraries, system services, web services, etc.], User oriented software [word processing [Ms word, spreadsheets, etc.], web services [google maps, facebook,

Technological context

Data (data sources [files, databases, data warehouses, etc.], access and privacy, data model, metadata, data integrity, quality and security, etc.)

Human-Computer Interactions-How to interact with hardware, software and data-(Interfaces [Human interfaces, e.g. nose, eye, hand, etc.; Computer interfaces, i.e. I/O peripherals e.g. keyboard, GUI, etc.], Interactions [input interaction, output interaction, interaction modality (e.g. multimodality), etc.])

Ambient and surrounding contexts
Social Group (Type [Family, Friends, Age Group, Community, Association], Needs, Affluence. i.e. resource possession, level of power, demography, etc.)

Culture (Language [oral, gestural, symbolic], Life Style [custom in dressing, feeding, entertainment, etc.], Norms [e.g. rules about obligations, authorizations, prohibitions, social hierarchy/organization (e.g.

Social context relationships between men and women), etc.], Beliefs [religions, taboos, etc.], etc.)

Social Resources (Type [goods/services (e.g. Food, water, education, health, employment, etc.)], availability, accessibility, management entity, etc.)

Power (Power type [Political, Economical, religious/ideological, cultural, etc.], power system [Anarchy, Theocracy, Monarchy, Democracy, etc.], Institutions, Laws/rules/procedures about business, etc.)

Atmospheric phenomena (Climate[seasons and their global characteristics such as average precipitation, temperature, humidity, etc.], Weather [day-to-day, and even hour-to-hour detailed atmospheric measures such as temperature, rain, sunshine, cloud cover, winds, heat waves, blizzards, fog, frost, flooding, light, pressure, etc.]) Environmental Surrounding ambiance (Indoor ambiance, Outdoor ambiance, strike ambiance, disturbing ambiance [noise,
context traffic jam, etc.], appropriate ambiance [calmness, privateness, etc.], joy ambiance [e.g. The company index gained 10 points], deception ambience, etc.)

Available services (Service type[transportation, healthcare, banking, car renting, hotels, etc.], service localization, service availability time, service cost, etc.)

Location (Location Type [Country, State/Province, City, District, Place, etc.], Location Name, Location address, Location Geometries (in 1D, 2D or 3D), Location POIs (Points of Interests), etc.)

Natural Geography Objects (Land Object [Mountain, Valley, Plain, etc.], Vegetation Object [prairie, forest, Savannah, etc.], Water Object [Watercourse, sea, ocean, etc.], Soil Object [Sand, Clay, etc.], Subsoil Object Spatial context [Gold, Oil, etc.], etc.)

Human Geography Objects (Housing infrastructures [buildings, houses, offices, etc.], Transportation infrastructures [Means (car, train, plane), Routes (roads, rails, airports, etc.)], Technological infrastructures [refers to technological context], etc.) 
- A raise of the importance of location-based contextualization of contextual information to better handle influences and information sharing between local and remote contexts;

- An organization of mobile GeoBI context into hierarchical context levels (personal, ambient and surrounding contexts) in accordance with human hierarchical perception of space;

- An inventory of detailed relevant contextual information for a mobile GeoBI context;

- etc.

The mobile GeoBI context model we have proposed in this paper is a generic one and has been intentionally limited to top-level concepts and basic challenges to ease its comprehension and show its capacity to support mobility as well as BI aspects while respecting an acceptable page limitation of this paper.

Ongoing work deals with the extension of this generic and top-level model with 1) detailed and somehow precise contextual information, context-aware applications should be aware of, and with 2) contextual metrics that will be introduced and integrated to boost its capacity to support contextual business analysis. The extension will then provide a more complete and fully BI-oriented model for implementation perspective. For contextreasoning purpose, the extension will be made using ontology-based formalism.

Further work will later deal with the implementation of the model and the challenge of coupling this complete context model with BI data structures and models (data warehouses, data cubes, etc.) in order to provide the users with appropriate contextual analytics on which they can base their decision process and take fully informed decisions.

\section{REFERENCES}

[1] A. Cuzzocrea, F. Furfaro and D. Saccam, "Hand-Olap: A System for Delivering Olap Services on Handheld Devices," International Symposium on Autonomous Decentralized Systems 2003, Pisa, 2003.

[2] A. Maniatis, "The Case for Mobile OLAP," 1st International Workshop on Pervasive Information Management (in Conjunction with EDBT'04), Heraklion, 2004.

[3] É. Dubé, T. Badard and Y. Bédard, "Service Web de Constitution en Temps Réel de Mini-Cubes SOLAP Pour Clients Mobiles," Atelier SIG Ubiquitaire-SIG Mobiles, CQFD-Géo/Sageo, Clermont-Ferrand, 2007.

[4] BusinessObject.com, "Getting Information Where and When You Need It," 2008. http://www.businessobjects.com/pdf/product/catalog/inf ormation_delivery/mobile/mobile_product_sheet.pdf

[5] IBM.com, "Cognos 8 Go! Mobile Extend Business Intelligence Value by Accessing Information on Mobile Devices," 2009.

http:/www-01.ibm.com/software/data/cognos/products/ cognos-8-go/mobile/

[6] D. J. Power, "Decision Support Systems: Concepts and Resources for Managers," Greenwood Publishing Group, Westport, 2002.

[7] M. Golfarelli, S. Rizzi and I. Cella, "Beyond Data Warehousing: What's Next in Business Intelligence?" DOLAP' 04 Proceedings, New York, 2004.

[8] D. Oard and G. Marchionini, "A conceptual Framework for Text Filtering," Technical Report EE-TR-96-25 CARTR-830 CLIS-TR-9602 CS-TR-3643, University of Maryland, College Park, 1996.

[9] J. Herring, "Building a Business Intelligence System," The Journal of Business Strategy, Vol. 9, No. 3, 1988, pp. 4-9. doi:10.1108/eb039219

[10] H. Luhn, “A Business Intelligence System," IBM Journal of Research and Development, Vol. 2, No. 4, 1958, pp. 314-319.

[11] S. Negash and G. Paul, "Business Intelligence," Handbook on Decision Support Systems, 2 Edition, Springer, Berlin, 2008, pp. 175-193.

[12] E. Turban, J. E. Aronson and T.-P. Liang, "Decision Support Systems and Intelligent Systems," Pearson Prentice Hall, Upper Saddle River, 2005.

[13] B. Evelson and N. Norman, "Topic Overview: Business Intelligence," Forrester Research, 2008.

http://www.forrester.com/rb/Research/topic_overview_bu siness_intelligence/q/id/39218/t/2

[14] M. Frolich and T. Ariyachandra, "Business Performance Management: One Truth," Information Systems Management, Vol. 23, No. 1, 2006, pp. 41-48. doi:10.1201/1078.10580530/45769.23.1.20061201/91771.5

[15] whatis.com, "Business Intelligence (BI)," 2009. http://searchdatamanagement.techtarget.com/sDefinition/ 0,sid91_gci213571,00.html

[16] C. Franklin, "An Introduction to Geographic Information Systems: Linking Maps to Databases," Database, Vol. 15, No. 2, 1992, pp. 13-21.

[17] J. Urry, "Mobility and Proximity," Sociology, Vol. 36, No. 2, 2002, pp. 255-274 doi: $10.1177 / 0038038502036002002$

[18] C. Bolchini, C. A. Curino, E. Quintarelli, L. Tanca and F. A. Schreiber, "A Data-Oriented Survey of Context Models," SIGMOD Record, Vol. 36, No. 4, 2007, pp. 19-26. doi: $10.1145 / 1361348.1361353$

[19] P. Lombardi, V. Cantoni and B. Zavidovique, "Context in Robotic Vision: Control for Real-Time Adaptation," International Conference on Informatics in Control, Automation and Robotics, 2004.

[20] G. Chen and D. Kotz, "A survey of Context-Aware Mobile Computing Research (Tech. Rep. TR2000-381)," Department of Computer Science, Dartmouth College, Hanover, 2000.

[21] B. Shilit, N. Adams and R. Want, "Context Aware Computing Applications," 1st International Workshop on Mobile Computing Systems and Applications, 1994. doi:10.1109/WMCSA.1994.16

[22] L. Sarjakoski and A.-M. Nivala, “Adaptation to Con- 
text-A Way to Improve the Usability of Mobile Maps," Map-Based Mobile Services, Theories, Methods and Implementations, Springer, Berlin, Heidelber, New York, 2005, pp. 107-123.

[23] L. Barkhuus and A. Dey, "Is Context-Aware Computing Taking Control away from the User? Three Levels of Interactivity Examined," Ubi-Comp2003 Conference, Lecture Notes in Computer Science 2864, 2003.

[24] A. K. Dey, "Providing Architectural Support for Building Context-Aware Applications, Doctoral Dissertation," Georgia Institute of Technology, 2000.

[25] R. Want, A. Hopper, V. Falcao and J. Gibbons, "The Active Badge Location System," ACM Transactions on Information Systems, Vol. 10, No. 1, 1992, pp. 91-102. doi:10.1145/128756.128759

[26] M. Weiser, "Some Computer Science Issues in Ubiquitous Computing," Communications of the ACM, Vol. 36, No. 7, 1993, pp. 75-84. doi:10.1145/159544.159617

[27] P. S. Tan, A. E. S. Goh and S. S. G. Lee, "A Context Model for B2B Collaborations," 2008 IEEE International Conference on Services Computing, 2008.

[28] P. Kumar, S. Gopalan and V. Sridhar, "Context Enabled Multi-CBR Based Recommendation Engine for Ecommerce," International Conference on E-Business Engineering, Beijing, 2005.

[29] W. Zheng and Y. Yuan, "Identifying the Differences between Stationary Office Support and Mobile Work Support: A Conceptual Framework," International Journal of Mobile Communications, Vol. 5, No. 1, 2007, pp. 107-122. doi:10.1504/IJMC.2007.011492

[30] H. Wigelius and H. VÄaÄatÄajÄa, "Dimensions of Context Affecting User Experience in Mobile Work," INTERACT'09: Proceedings of the 12th IFIPTC 13 International Conference on Human-Computer Interaction, Berlin, 2009.

[31] V. Roto, "Web Browsing on Mobile Phones - Characteristics of User Experience, Espoo, Finland," Ph.D. Dissertation, Helsinki University of Technology, Helsinki, 2006.

[32] B. Schilit and M. Theimer, "Disseminating Active Map Information to Mobile Hosts," IEEE Network, Vol. 8, No. 5, 1994, pp. 22-32. doi:10.1109/65.313011

[33] M. F. Mokbel and J. J. Levandoski, "Toward Context and Preference-Aware Location-Based Services," Proceedings of the Eighth ACM International Workshop on Data Engineering for Wireless and Mobile Access, 2009. doi:10.1145/1594139.1594150

[34] T. S. W. Hofer, M. Pichler, G. Leonhartsberger and J. Altmann, "Context-Awareness on Mobile Devices-The Hydrogen Approach," Proceedings of the 36th Annual Hawaii International Conference on System Sciences, Hawaii, 2002.

[35] N. Bradley and M. Dunlop, "Toward a Multidisciplinary Model of Context to Support Context-Aware Computing," Human-Computer Interaction, Vol. 20, No. 4, 2005, pp. 403-436. doi:10.1207/s15327051hci2004_2

[36] A. Dey, G. Abowd and D. Salber, "A Conceptual Framework and a Toolkit for Supporting the Rapid Prototyping of Context-Aware Applications," Human-Computer In- teraction, Vol. 16, No. 2-4, 2001, pp. 97-166. doi:10.1207/S15327051HCI1623402

[37] T. Winograd, "Architectures for Context," Human-Computer Interaction (HCI) Journal, Vol. 16, No. 2, 2001, pp. 401-419.

[38] B. Shilit, N. Adams and R. Want, "Context Aware Computing Applications," 1st International Workshop on Mobile Computing Systems and Applications, 1994. doi:10.1109/WMCSA.1994.16

[39] B. Tversky, "Structures of Mental Spaces: How People Think About Space," Environment and Behaviour, Vol. 35 , No. 1,2003 , pp. $66-80$. doi: $10.1177 / 0013916502238865$

[40] I. Reginster and G. Edwards, "The Concept and Implementation of Perceptual Regions As Hierarchical Spatial Units for Evaluating Environmental Sensitivity," Journal of Urban and Regional Information Systems Association, Vol. 13, No. 1, 2001, pp. 5-16.

[41] A. Schmidt, M. Beigl and H.-W. Gellersen, "There Is More to Context than Location," Computers and Graphics, Vol. 23, No. 6, 1999, pp. 893-901. doi:10.1016/S0097-8493(99)00120-X

[42] A. Kofod-Petersen and M. Mikalsen, "Context: Representation and Reasoning-Representing and Reasoning about Context in a Mobile Environment," Revue d'Intelligence Artificielle, Vol. 19, No. 3, 2005, pp. 479-498. doi:10.3166/ria.19.479-498

[43] J. Gwizdka, "What's in the Context," Computer Human Interaction, 2000.

[44] G. Chen and D. Kotz, "A survey of Context-Aware Mobile Computing Research," Technical Report TR2000381, Dartmouth, 2000.

[45] L. Arhippainen and M. Tähti, "Empirical Evaluation of User Experience in Two Adaptive Mobile Application Prototypes," Proceedings of the 2nd International Conference on Mobile and Ubiquitous Multimedia, Norrköping, 2003.

[46] L. Niu, J. Lu and G. Zhang, "Cognition-Driven Decision Processes," Cognition-Driven Decision Support for Business Intelligence, Springer, Berlin/Heidelberg, 2009, pp. 53-73. doi:10.1007/978-3-642-03208-0_5

[47] M. Endsley, "Towards a Theory of Situation Awareness in Dynamic Systems," Human Factors, Vol. 37, No. 1, 1995, pp. 32-64. doi:10.1518/001872095779049543

[48] L. Niu, J. Lu and G. Zhang, "Managerial Cognition," in Cognition-Driven Decision Support for Business Intelligence, Springer, Berlin/Heidelberg, 2009, pp. 31-37. doi:10.1007/978-3-642-03208-0 3

[49] M. Stanners and H. French, "An Empirical Study of the Relationship between Situation Awareness and Decision Making," Technical Report DSTO-TR-1687 of the Defence Science and Technology Organisation, 2005. www.dsto.defence.gov.au/corporate/reports/DSTO-TR-16 87.pdf

[50] P. Jordan, S. Lawrence and A. Troth, "The Impact of Negative Mood on Team Performance," Journal of Management \& Organization, Vol. 12, No. 2, 2006, pp. 131145 . 
doi:10.5172/jmo.2006.12.2.131

[51] J. R. Nofsinger, "Social mood and Financial Economics," Journal of Behavioral Finance, Vol. 6, No. 3, 2005, pp. 144-160. doi:10.1207/s15427579jpfm0603_4

[52] N. Randewich, "Intel Guru: Future Phones Will Sense Your Mood," International Business Times, 15 September 2010 .

http://www.ibtimes.com/articles/62682/20100915/intel-gurufuture-phones-will-sense-your-mood.htm\#

[53] N. Bradley and M. Dunlop, "Toward a Multidisciplinary Model of Context to Support Context-Aware Computing," Human-Computer Interaction, Vol. 20, No. 4, 2005 , pp. 403-436. doi:10.1207/s15327051hci2004_2

[54] Y. Bédard, "Principles of Spatial Database Analysis and Design," In: GIS: Principles, Techniques, Applications \& Management, 2nd Edition, Chapter 29, Wiley, New York, 1999, pp. 413-424.

[55] S. Tamminen, A. Oulasvirta, K. Toiskallio and A. Kankainen, "Understanding Mobile Contexts," Personal and Ubiquitous Computing, Vol. 8, No. 2, 2004, pp. 135-143. doi:10.1007/s00779-004-0263-1

[56] R. J. Thierauf, "Effective Business Inteligence Systems," Quorom Books, Westport, 2001. 